\title{
COPING E ADOECIMENTO CARDÍACO EM UM TRABALHADOR DA SAÚDE
}

\author{
Coping and heart illness in a health worker
}

\begin{abstract}
Kleber dos Santos ${ }^{\mathrm{a}}$, Luana Martendal ${ }^{\mathrm{b}}$

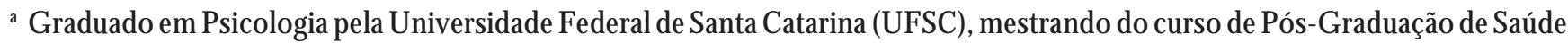
Pública da UFSC. São José, SC - Brasil, e-mail: kleberpsicometria@ yahoo.com.br

b Possui graduação em Psicologia pela Universidade do Vale do Itajaí. A tualmenteécolaboradora da Universidade Federal deSanta Catarina. Itajaí, SC - Brasil, e-mail: luana42@ hotmail.com
\end{abstract}

\section{Resumo}

A O rganização Mundial do Trabalho desde a década de 1940 considera problemática as condições de trabalho dos profissionais da saúde. Os ambientes em que atua esse grupo ocupacional apresentam riscos, em especial biológicos, químicos e de acidentes. 0 objetivo desta pesquisa foi investigar por meio de um estudo de caso a relação entre a atividade de trabalho e a saúde de um técnico de enfermagem com 34 anos de experiência, e destacar os fenômenos psicoló gicos presentes nessa relação. A coleta de dados foi realizada com observações diretas assistemáticas e entrevistas semiestruturadas. 0 resultado do cruzamento das evidências empíricas mostrou que as variáveis excesso de carga horária, turnos alternados e ausência de acidentes de trabalho foram as que apresentaram maior relação com os fenômenos psicológicos envolvidos no desempenho das funções do participante ao longo de seu itinerário ocupacional. D urante 10 anos ele desempenhou suas atividades sob um regime de 28 horas ininterruptas em estado de vigília. 0 modelo de demanda e controle de Karasek auxiliou na compreensão da contribuição dessas condições de trabalho para o surgimento de uma arritmia cardíaca. A ausência de acidentes de trabalho no histórico ocupacional do participante foi conjeturada como resultado do coping eficaz manifestado por ele nas situações de estresse ocupacional desde o início como trabalhador da saúde.

Palavras-chave: Saúde; Trabalho; Cardiopatia; Estresse ocupacional; C oping. 


\begin{abstract}
The International Labour Organization considers problematic the conditions of work of the professionals of the health since the decade of 1940. The environments where this occupational group acts present risks, specially biological, chemical and of accidents. The aim of this research was to investigate by case study the relationship between work activity and health of a nursing technician with 34 years of experience and to emphasize the psychological phenomena presents in this relationship. The data collection was realized by no systematic direct observations and semi-structured interviews. Results derived from the crossing of empirical evidences has shown that variables hour load excess, alternate shifts and absence of work accidents were those had a greater relationship with the psychological phenomena involved in the participant's work throughout his occupational history. For 10 years he had executed his activities under a system of 28 uninterrupted hours in a state of wakefulness. Karasek's job strain model help to understand the contribution of mentioned work conditions for the emergence cardiac arrhythmia. The fact of absence of work accidents in the occupational history was hypothesized how the result of the coping expressed by him since his beginning health worker.
\end{abstract}

Keywords: Health; Work; Heart illness; Job stress; Coping.

\section{INTRODUÇÃO}

A O rganização Mundial do Trabalho (OIT) desde a década de 1940 considera difíceis as condições de trabalho dos profissionais da saúde de vários países (Marziale \& Robazzi, 2000). Há fatores no ambiente hospitalar que incidem na saúde nessa categoria profissional, por exemplo: desenho dos equipamentos; posto de trabalho; maneira que a atividade é executada; comunicação; ambiência, como iluminação e temperatura. Fadiga mental e sofrimento psíquico são manifestados pelos profissionais da saúde.

0 contexto enseja investigações a fim de apresentar diagnósticos que fundamentem intervenções eficazes na mudança do trabalho. A Psicologia do Trabalho éumaárea de conhecimento profícuano processo de diagnóstico e intervenção em ambientes organizacionais, pois busca compreender e explicar os fenômenos psicológicos presentes na atividade de trabalho tomando como referência as condições estabelecidas pelo meio sociotécnico (Azevedo \& Cruz, 2006). Ambientes hospitalares são um dos campos de atuação da Psicologia do Trabalho.

\section{Carga de trabalho e riscos ocupacionais}

O construto carga de trabalho apresenta ambiguidade na literatura específica da E rgonomia, pois, pode referir-se tanto ao grau de exigências da atividade profissional como às consequências desta (Falzon \& Sauvagnac, 2007). A carga de trabalho também pode ser compreendida como uma relação funcional das tensões existentes entre as exigências da tarefa e as capacidades psicofisiológicas de resposta do trabalhador (Frutuoso \& Cruz, 2005). Pode-se fazer uma analogia com uma balança (Figura 1, parte inferior), 0 equilíbrio entre as duas variáveis suscita a saúde, enquanto o desequilíbrio oportuniza o adoecimento. Esse desequilíbrio pode aparecer de duas formas: como uma sobrecarga que indica uma superestimação, ou seja, as exigências estão além das capacidades de resposta do trabalhador; ou como uma subcarga, as exigências estão aquém de suas capacidades, o que representa uma subestimação. 


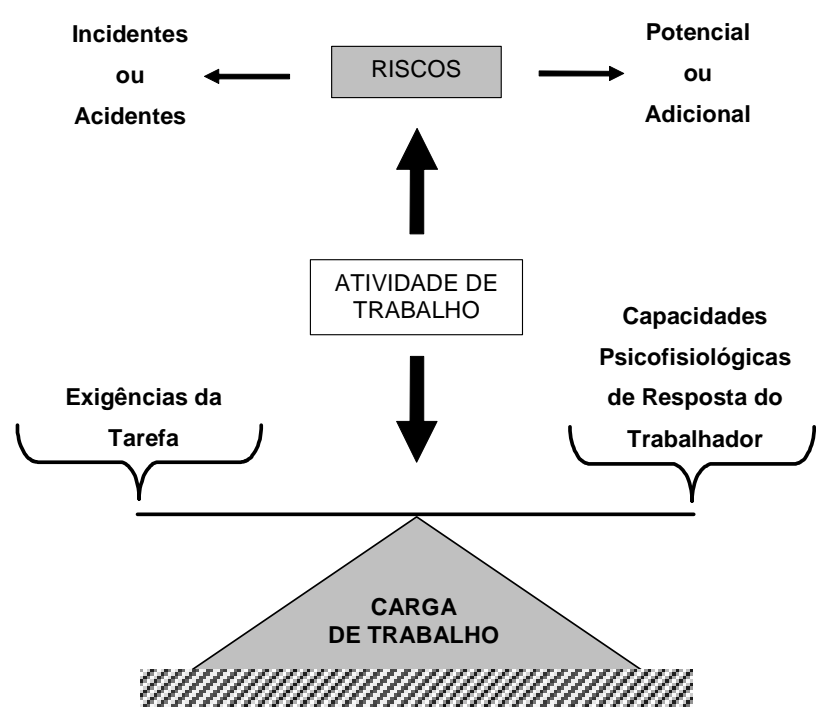

FIG URA 1 - Atividadedetrabalho eosriscosocupacionais, parte superior da figura, e a relação funcional da carga de trabalho, parte inferior (Fonte: Cruz, 2007)
A Figura 1 também mostra como em uma atividade de trabalho os riscos ocupacionais podem estar relacionados com a carga de trabalho. O s critérios para a categorização dos riscos nessa situação estão pautados na natureza dele ser potencial (se o risco potencializa o surgimento do perigo) ou adicional (se à medida que o tempo passa e o profissional se expõe ao risco, aumentam as chances do surgimento do perigo), e quanto à capacidade de gerarem incidentes ou acidentes. 0 desequilíbrio entre as exigências da tarefa e as capacidades psicofisiológicas de respostas podem agravar a incidência de riscos adicionais ou potenciais, e proporcionar incidentes e/ ou acidentes de trabalho. A Norma Regulamentadora № 9 (Ministério do Trabalho, 1994a) junto com a portaria $\mathrm{n}^{\mathbf{0}}$ 25, de 29 de dezembro de 1994 (Ministério do Trabalho, 1994b) delimitam os agentes de risco ocupacional em 5 categorias, como mostra a Tabela 1.

TABELA 1 - Classificação dos riscos ocupacionais (Fonte: Ministério do Trabalho, 1994a; 1994b)

\begin{tabular}{ll}
\hline Grupo de Risco O cupacional & Agentes \\
\hline Físicos & Ruído, vibrações, radiações ionizantes e não ionizantes, temperaturas extremas (frio e \\
& calor), pressões anormais, umidades. \\
Químicos & Poeiras, fumos, névoas, neblinas, gases, vapores, produtos químicos em geral. \\
Biológicos & Vírus, bactérias, protozoários, fungos, parasitas, bacilos. \\
Ergonômicos & Esforço físico intenso, levantamento etransportemanual depeso, exigênciadepostura \\
& inadequada, controlerígido deprodutividade, imposição deritmos excessivos, trabalho \\
& em turno e noturno, jomadas de trabalho prolongadas, monotonia e repetitividade, \\
& outras situações causadores deestressefísico epsicológico. \\
Acidentes & Arranjo físico inadequado, máquinas e equipamentos sem proteção, ferramentas \\
& inadequadas ou defeituosas, iluminação inadequada, eletricidade, probabilidade de \\
& incidência de explosão, armazenamento inadequado, animais peçonhentos, outras \\
& situações derisco quecontribuem paraocorrênciadeacidentes.
\end{tabular}

\section{Estresse e coping no trabalho}

O estresse ocupacional de acordo com Jex (1998) deve ser entendido de acordo com três aspectos. O primeiro, os estímulos estressores, sendo 0 estresse ocupacional relativo aos estímulos do contexto organizacional, conhecidos como estressores organizacionais, eles exigem respostas adaptativas porparte do trabalhador eque excedem sua habilidade de enfrentamento ou coping. 0 segundo aspecto concerne às respostas psicológicas, comportamentais e fisiológicas dos trabalhadores aos estressores organizacionais. Por último, há os estímulos estressores-respostas, é o impacto nos trabalhadores dos processos organizacionais com seus estímulos estressores. Essa conceituação possibilita a diferenciação dos estressores ocupacional e do estresse em geral a partir do enfoque nos estressores organizacionais.

Em 1979, Robert A. Karasek publicou o artigo científico Job demands, job decision latitude, and mental strain: implications for job redesign, no qual mostrava à comunidade científica um novo paradigma, à época, para compreender 0 estresse 
ocupacional. Esse método foi denominado modelo de demanda-controle (Figura 2), e é utilizado para dimensionaratensão psicológica, que o autorpostula como uma das facetas do estresse ocupacional. Ela é a resultante do confronto das variáveis exigência ou demanda psicológica no trabalho com a margem de decisão ou o controle que o trabalhador apresenta sobre sua atividade (Karasek, 2001). Cada uma dessas duas dimensões psicossociais da atividade de trabalho apresenta um nível de mensuração dicotômico: alto ou baixo. O cruzamento desses oferece quatro tipos situações e duas diagonais, as quais correspondem (A) à saúde física e psicológica do trabalhador e (B) à motivação de aprendizagem do trabalhador para desenvolver novas pautas de comportamentos.

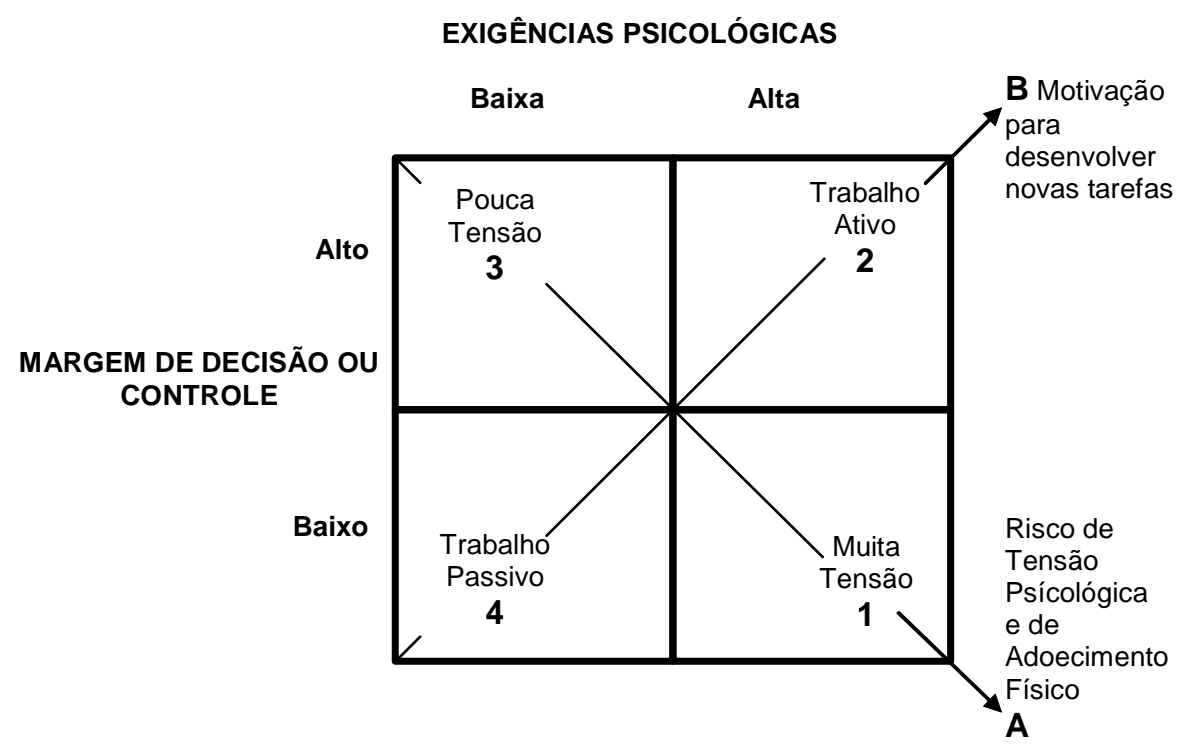

FIGURA 2 - Representação do modelo demanda-controle de Karasek Fonte: KARASE K, 1979.

Lazarus (1966) cunhou um conceito de estresse que abrange os fatores estímulo ou identificação do agente estressor, resposta, avaliação cognitiva da ameaça, estilos de enfrentamento ou coping, defesas psicológicas e meio social. Lazarus e Folkman (1984a) definem coping como as estratégias que as pessoas geralmente utilizam diante da situação de estresse, e que depende dos fatores pessoais, situacionais e dos recursos disponíveis. O s mesmos autores (Lazarus \& Folkman, 1984b) classificam o enfrentamento centrado nos problemas - que consiste na busca de informação para resolução do problema - ou nas emoções - expressão e regulação das emoções.

O coping também pode ser investigado no ambiente ocupacional. A eficácia desse empreendimento está relacionada com a identificação dos agentes estressores ocupacionais, haja vista que paracompreendero opingénecessário compreender os agentes desencadeadores de estresse. Tal conhecimento reflete-se nas pesquisas que investigaram o coping de trabalhadores no Brasil (Murta \& Tróccoli, 2007; Pinheiro, Tamayo \& Tróccoli, 2003; Tamayo \& Tróccoli, 2002).

\section{Aspectos relativos à saúde e segurança ocupacional dos profissionais da saúde}

A divisão do trabalho em forma de turnos existe desde 0 início da vida social da humanidade, atualmente os turnos são aplicados por motivos socioeconômicos e tecnológicos (Fisher, Teixeira, Borges, G onçalves \& Ferreira, 2002). O s profissionais da saúde pertencem a um dos grupos mais antigos a utilizar o sistema de turnos na gestão organizacional.

Costa, Morita e Martinez (2000) realizaram uma pesquisa cujo objetivo foi identificar o sistema de turnos da equipe de enfermagem em um hospital universitário, eavaliar a influência dessa variável ocupacional sobre a saúde, vida social eparticipação desses funcionários 
na organização da jornada de trabalho. Três instâncias da vida social foram percebidas como sofrendo interferências devido ao turno de trabalho: 0 relacionamento pessoal e a vida familiar; as atividades sociais; e a dificuldade de planejar a vida. O s resultados demonstraram que os aspectos de saúde mais citados foram distúrbios neuropsíquicos, cardiovasculares e gastrintestinais.

A Norma Regulamentadora № 32, conhecida como NR 32, publicada em 2005 pelo Ministério do Trabalho tem como objetivo estabelecer os princípios básicos paraimplementação de medidas de proteção e prevenção à saúde e segurança dos profissionais da saúde. A cartilha do trabalhador da enfermagem (Associação Brasileira de Enfermagem do Rio de Janeiro [ABE/ RJ], 2006) apresenta uma listagem dos principais riscos ocupacionais encontrados nos ambientes hospitalares. D entre os biológicos, apresentam como mais comuns a tuberculose pulmonar, ccytomegalovirus (CMV), hepatites virais (B eC), síndromedaimunodeficiência adquirida (HIV) e infecção proveniente do HIV. Dentre os químicos encontram-se os anestésicos, detergentes, esterilizantes, desinfetantes, solventes, agentes de limpeza, antissépticos, detergentes, medicamentos e drogas de risco. Os riscos físicos mais comuns no ambiente hospitalar são as radiações ionizantes e as vibrações oscilatórias. Os riscos ergonômicos e de acidentes de trabalho são influenciados pelas condições de trabalho, que seriam o conjunto de fatores composto pelas exigências da função, organização, execução, remuneração e ambiente ocupacional, capazes de determinar a conduta do trabalhador. As consequências do estado físico e psicológico do trabalhador são: satisfação, conforto, carga de trabalho, fadiga, estresse, doenças e acidentes de trabalho.

$\mathrm{O}$ ferimento com materiaisperfurocortantes no ambiente hospitalar potencializa a contaminação pelosagentesbiológicos (O sório, Machado \& MinayoGomez, 2005). D epois do surgimento da Síndrome da Imunodeficiência Adquirida (AIDS) e as descobertas sobre a hepatite $C$, os acidentes de trabalho com perfurocortantese exposição aosfluídos biológicos passou a haver maior preocupação com a segurança dos trabalhadores da saúde. Balsamo e Felli (2006) realizaram uma pesquisa exploratória com 48 funcionários do Hospital Universitário (HU) da Universidade de São Paulo (USP) que sofreram acidentes de trabalho com exposição de líquidos corporais humanos. Os resultados apontaram que em 87,50\% da amostra o agente causador do acidente foram os perfurocortantes. Nishide, Benatti e Alexandre (2004) realizaram estudo descritivo transversal cujo escopo era investigar a correlação entre os acidentes de trabalho ocorridos com os profissionais da saúde de unidade de terapiaintensiva (UTI) e os procedimentos que estavam sendo realizados no momento do acidente. 0 resultado demonstrou a prevalência do contato da mucosa com sangue e secreções, ferimento com material perfurocortante, queda e lesões na coluna vertebral.

No Estado de Santa Catarina há pesquisas quemostramíndicesrelativosaosacidentes detrabalho e aos agentes na sobrecarga ocupacional. Campos (2006) mostra como as variáveis turno de trabalho, pressão do tempo, elevada responsabilidade em salvar vidashumanas, eosriscosdecontaminação debactérias e vírus são os que mais contribuem para a carga e sobrecarga ocupacional nos servidores públicos da saúde do Estado de Santa Catarina. Nessa mesma categoria profissional foi investigado o perfil dos acidentes de trabalho notificados através da comunicação estadual deacidentes detrabalho (Boclin, 2007). Os resultados apontam que, dentre todas as secretarias do Estado, a da saúde foi aquela com maior prevalência de acidentes (90,50\%), que ocorreram em sua maioria nas enfermarias das instituições de saúde $(25,94 \%)$ com perfurocortantes (32,37\%).

A pesquisa relatadanesteartigo éum estudo de caso cujo objetivo foi investigar a relação entre a atividade de trabalho e a saúde de um trabalhador da saúde ao longo do seu histórico ocupacional. Priorizou-se compreender os fenômenos eprocessos psicológicos presentes nessa relação.

\section{MÉTODO}

O delineamento metodológico utilizado foi um estudo de caso. Essa metodologia tem como objetivos (1) uma investigação empírica de um fenômeno dentro de seu contexto de vida real, (2) e enfrenta uma situação tecnicamente única em que há muito mais variáveis envolvidas além das que compõem o foco do pesquisador, bem como leva em consideração várias fontes de evidência com seus dados convergindo para uma triangulação (Y in, 2005). 


\section{Participante}

O participante foi um trabalhador da área da saúde que há 34 anos desempenha a atividade de técnico de enfermagem, é brasileiro, natural de Santa Catarina, casado, pai de doisfilhos. Antes deiniciarmos a pesquisa, conforme o item IV da resolução 196/ 96 do Conselho Nacional de Saúde (1996), o participante foi consultado quanto a seu consentimento de ser sujeito de uma pesquisa que investigaria sua vida ocupacional, bem como a etapa final, que visava sua publicação em um periódico de circulação nacional. Ele concordou em ser participante.

\section{Instrumentos}

Foram utilizados dois instrumentos para coleta de dados, observação direta assistemática e entrevista semiestruturada. O primeiro consiste em coletar dados da realidade sem meios técnicos especiais ou controle, geralmente éconsideradacomo umaferramentaexploratóriaparareconhecero campo a ser investigado (Lakatos \& Marconi, 1996).

A entrevista semiestruturada é um instrumento que permite ao pesquisador investigar os pontos de vista do entrevistado com um planejamento mais aberto do que uma entrevista padronizada ou um questionário (Flick, 2004), ela também fornece condições para que se direcione mais a coleta de dadosparatópicosmaisespecíficos. Foram construídas duas entrevistas semiestruturadas. A primeira teve como escopo perscrutar as macrovariáveis ocupacionais: histórico, adoecimento e atividade de trabalho atual. Na segunda, procurou-se checar os fenômenos psicológicos relacionados às variáveis ocupacionais, bem como esclarecer as dúvidas que surgiram das observações diretas assistemáticas.

\section{Procedimentos}

A coleta de dados foi realizada pelos pesquisadores em um período de três semanas, por meio de quatro visitas ao posto de trabalho atual do participante. Na primeira visita houve observação direta assistemática da atividade de trabalho atual do profissional da saúde, e aplicação da primeira entrevista semiestruturada. A segunda e a terceira visita consistiram apenas em observações diretas assistemáticas. Na quarta e última visita foi realizada a segunda entrevista semiestruturada. Todas as visitas tiveram duração de uma a duas horas.

\section{RESULTADOS}

\section{H istórico ocupacional}

0 participante da pesquisa tem 52 anos de idade. Formou-se há aproximadamente 34 anos em técnico de enfermagem e auxiliar de enfermagem do trabalho. Começou em 1974, aos 18 anos de idade, como profissional da saúde na UTI de um hospital no Estado de Santa Catarina no turno diurno, com carga horária de 12 horas e folga de 36 horas. D epois de três anos, passou também a atuar em outra instituição de saúde, porém, no turno da noite sob um regime de 12 horas de trabalho e 60 horas de descanso. Seu cargo era técnico de enfermagem da supervisão geral da instituição, sua atividade consistia em atender qualquer ala da instituição onde os profissionais da saúde estivessem com dificuldades para desempenhar suas tarefas.

0 hospital em que atuava durante 0 dia liberava-o aos sábados para ministrar treinamento de primeiros socorros em uma unidade de ensino da Secretaria de Segurança Pública do Estado de Santa Catarina (SSP/ SC). Essa função foi desempenhada entre 1978 e 1982. Na mesma época, foi professor de um curso da área da saúde em uma escola profissionalizante. Além das quatro funções, era auxiliar deenfermagem do trabalho em uma empresa de vigilância.

Em 1982, deixou a instituição de saúde em que atuava no turno diurno para tornar-se instrutor de primeiros socorros e técnico de enfermagem de uma empresa, com carga horária de 40 horas semanais. Gradativamente essa instituição 0 obrigou a deixar as outras funções, restando somente o hospital no qual era plantonista no período noturno. 0 regime de turnos nessa instituição permaneceu o mesmo, contudo, passou a atuar na UTI, posto de trabalho em que era proibido intervalo de descanso, sendo as funções mínimas monitorar os sinais vitais dos pacientes, principalmente aqueles em situação de pós-operatório. 0 ciclo de monitoramento era de 15 minutos. 
0 participante, motivado principalmente porquestõesfinanceiras, atuou nessas duas atividades que lhe exigiam permanecer em estado de vigília de 28 horas ininterruptas ao longo de aproximadamente 10 anos. No final da década de 1980 o profissional da saúde relatou que passou a apresentar arritmia cardíaca. Percebia seu batimento cardíaco acelerar no desempenho de sua função quando estava com muito sono e esforçava-se para continuar acordado, disse o participante: "... dava um desespero quando o sono vinha e eu tinha que lutar para continuar acordado. D ava vontade de sair correndo e dormir. O sono é pior que o cansaço físico." Houve três situações em que sua arritmia alcançou um quadro de fibrilação atrial: em duas delasos médicos conseguiram fazer a reversão por meio da farmacoterapia; em uma outraeletevedereceberchoque. Nessestrês episódios dearritmiacardíacaocorreram osúnicosafastamentos que o participante teve em toda sua vida profissional. A carga horária excessiva também ocasionou problemasdeordem social. Ficou alheio àconvivência familiar, relatou que só via os filhos quando chegava a casa à noite, e, geralmente, eles estavam dormindo. Deixou de participar de muitas festas de família porque estava no plantão de final de semana, nessas situações a esposa ficava em casa, mesmo tendo a possibilidadedeircom osfilhos atéa reunião familiar, ela dizia que não tinha graça a família ir sem ele. Nesse ínterim houve isolamento do convívio social.

Depois da situação de adoecimento cardíaco, ele optou por trocar a atividade de plantonista da UTI por técnico de enfermagem da instituição penal, local onde as exigências com a carga horária são mais flexíveis e a atividade permite a ele pausas para descanso. Também relatou que depois de todo aquele tempo dormindo tão pouco, seu organismo se satisfaz com uma curta noite de sono, em média quatro horas. Essa foi a atividade de trabalho objeto da observação direta assistemática desta pesquisa. Verificou-se, pelo relato do participante, que os postos de trabalho em que 0 profissional interagiu e interage diretamente com pacientes na função de técnico de enfermagem foi na supervisão geral de um hospital, no plantão diurno e noturno de UTI e no ambulatório médico de uma instituição penal.

Ao longo de seus 34 anos como trabalhador da saúde nunca sofreu um acidente de trabalho. Os pesquisadores o questionaram sobre o queelepensava que contribui para a manutenção da ausência de acidentes em seu histórico ocupacional. Ele respondeu que, desde o início como profissional da saúde, sempre cuidou para manter o controle de suas emoções, sem pânico e movimentos muito rápidos, bem como mantém toda atenção possível nos procedimentos que executa ao desempenhar sua função. Essa atitude também é utilizada por ele como uma forma de cuidar para que o ambiente com pessoas enfermas não se torne mais desconfortável do queé normalmente, evitando que o sofrimento do paciente se intensifique. Os dados coletados nas observações diretas assistemáticas corroboram essa resposta do participante.

\section{Atividade de trabalho atual}

O ambulatório médico é uma sala com aproximadamente 3 metros de comprimento e de largura, e 2,5 metros de altura. Existem alguns móveis, dentre eles um armário que divide a sala em dois ambientes, um mais exposto àqueles que circulam pela instituição e em que são recebidas as pessoas quando chegam ao ambulatório, eoutro mais reservado, onde se faz procedimentos que envolvem cuidados mais precisos. Nesse há uma maca e duas pias. Todo 0 ambulatório médico é iluminado por quatro luminárias, cadaqual com duas lâmpadas fluorescentes brancas, que estavam funcionando em bom estado durante as visitas dos pesquisadores. Neste ínterim também foi notificado que 0 ambiente estava higienizado, não apresentava temperaturas e pressões extremas. Foi observada ausência de partículas de poeira ou de qualquer outra natureza suspensas no ar.

$\mathrm{Na}$ atividade de trabalho atual como técnico de enfermagem de ambulatório médico de uma instituição penal do Estado de Santa Catarina, 0 participante deste estudo deve basicamente: auxiliar o médico do ambulatório nas consultas com os pacientes, que são os detentos da instituição; verificar os sinais vitais, como pressão arterial (PA), batimentos cardíacos (BC) e respiração; limpar, medicare/ ou fazer curativos em ferimentos; preparar as medicações prescritas pelo médico e entregá-las ao detento. Durante todos esses procedimentos é colocado como tarefa prescrita sempre tratar com respeito o detento que necessita de seus cuidados como qualquer outro usuário do serviço de saúde pública, que sempre é conduzido pelo agente prisional ao ambulatório médico. 0 participante da pesquisa atendeu alguns detentos durante as visitas dos pesquisadores, sendo que em alguns casos 
bastou uma orientação de como proceder com a medicação conforme a prescrição médica, e outros em que 0 detento foi atendido devido a ferimentos.

Há situações em que um detento necessita de atendimento emergencial em sua cela, ou está em outras alas e carece de cuidados relativos à saúde. Nessas ocasiões, o técnico de enfermagem desloca-se até o local onde se encontra o interno e, então, esse ambiente também se torna seu posto de trabalho. Quando começou a trabalhar na instituição, mesmo sendo lotado no ambulatório, o participante realizava os atendimentos nos corredores. Ele se deslocava à cela do detento que necessitava de atendimento, este era algemado pelo agente prisional e colocado no corredor. Houve noites em que chegou a atender 49 detentos. D epois de alguns anos, passou a fazer os atendimentos na barbearia que ficava mais próxima às celas, os agentes prisionais conduziam os detentos até lá. A decisão de modificar seu posto de trabalho dos corredores para a barbearia e para 0 ambulatório médico foi tomada por medida de segurança.

Os pesquisadores identificaram o risco de natureza biológica como a categoria de risco ocupacional mais presente na atividade de trabalho observada. Existem vários internos contaminados com o vírus HIV, nem todos desenvolveram AID S. Aqueles em que a doença se manifestou recebem da equipedo ambulatório médico o kit demedicamentos para auxiliar no controle da doença. Há casos de tuberculose que também são controlados com medicamentos administrados pelos funcionários do ambulatório médico. O correm também casos de hepatite B e C, bem como outras doenças.

O participanterelatou conhecerosinternos que recebem medicamentos para controlar a AID S e a tuberculose, por isso, em seu posto de trabalho, quando atende um deles, seu cuidado aumenta durante os procedimentos de enfermagem e sempre utiliza luvas de procedimento, que são um dos equipamentos de proteção individual (EPI) dos profissionais da saúde. $\mathrm{O}$ técnico de enfermagem diminui seu rigor em relação a esse EPI quando os demais detentos que necessitam de cuidados médicos apresentam a pele sem ferimentos ou ausência de secreções corporais, e suas mãos estão sem ferimentos. As luvas de procedimentos sempre são utilizadas quando o detento tem um ferimento que necessita ser limpo, medicado e protegido. Nessas situações, geralmente há presença de secreções e, por meio delas, os agentes biológicos tornam-se riscos ocupacionais potenciais à saúde. Durante as visitas dos pesquisadores, quando o profissional da saúde atendeu os internos devido aos ferimentos, não utilizou óculos de proteção às secreções e ao sangue que podem ser projetados do corpo do paciente, sendo esse o maior risco do material biológico entrar em contato com as mucosas (olhos, nariz e boca) do profissional.

Outro risco ocupacional identificado foram situações que oportunizam a ocorrência de acidentes de trabalho, principalmente quanto ao uso de instrumentosperfurocortantes. A instituição prisional em que o participante da pesquisa atua é similar às demais em relação à fuga de detentos, rebeliões e estados de humor alterados entre detentos e agentes prisionais; durante tais momentos, os serviços do trabalhador da saúde podem ser necessários. Ao vivenciar essas situações, o profissional da saúde tem seu desempenho daatividade de trabalho afetado pois ocorre constrangimento - aqui empregado no sentido ergonômico, ou seja, qualquer redução da margem de manobra do trabalhador em seu posto de trabalho. Por isso, tais situações foram consideradas riscos eminentes a acidentes de trabalho, especialmente com material perfurocortante. 0 participante desta pesquisa passou por todas as três situações citadas anteriormente, inclusive houve uma rebelião na qual os detentos solicitaram seus serviços no local onde estavam amotinados. Com a permissão de seus superiores, ele foi até lá, sob a vigilância dos colegas da segurança pública, cuidou dos ferimentos dos detentos e depois retornou.

Quanto às exigências biomecânicas do técnico de enfermagem no ambulatório médico, observou-sequenamaiorpartedo tempo permanece sentado. Utiliza o computador que háno ambulatório médico somente para verificar marcações de consulta ou procedimentos medicamentosos prescritos pelo médico da instituição. Deambula pelo posto detrabalho com maiorfrequência quando realiza procedimentos de enfermagem que visam tratar de um ferimento ou algo do gênero. D urante seu turno também caminha pelo corredor parafazer as refeições ou ir ao banheiro. O técnico de enfermagem não foi observado em um atendimento nos corredores da instituição, tampouco em outras alas, por isso, não se fez registros das exigências posturais do profissional nesses postos de trabalho.

No que tange às exigências psicológicas da atividade de trabalho de técnico de enfermagem do ambulatório médico da instituição, foram 
observados como fenômenos psicológicos mais requeridos: atenção concentrada; memória de curto prazo ou memória de trabalho; memória de longo prazo; coping ou estratégias de enfrentamento frente aos agentes estressores da organização; habilidade social para lidar com os pacientes e com os demais colegas da instituição.

\section{DISCUSSÃO}

Em um estudo de caso é necessário que o pesquisador faça um cruzamento das evidências empíricas a fim de selecionar as variáveis mais importantes para a compreensão do fenômeno investigado (Y in, 2005). Nesta pesquisa foram selecionadas as variáveis: excesso de carga horária, turnos alternados eausência de acidentes de trabalho, pois apresentaram relação com os fenômenos psicológicos mais pertinentes tanto na atividade de trabalho como profissional da saúde.

\section{Excesso de carga horária, turnos alternados e adoecimento cardíaco}

As variáveis ocupacionais excesso de carga horária e turno alternado de trabalho são agentes que ocupam a categoria de risco ergonômico (Tabela 1) (Ministério do Trabalho, 1994b). 0 excesso de carga horária e os turnos alternados identificados neste estudo de caso contemplam o que Jex (1998) descreve como um agente estressor ocupacional. A literatura aponta que a intensidade dessas variáveis são consideráveis para ocasionar adoecimento à saúde do trabalhador, principalmente se o tempo de exposição a ela torna-se prolongado (Barthe, Gadbois, PrunierPoulmaire \& Quéinnec, 2007; Kogi, 2001). Os efeitos da privação de sono devido às exigências do desempenho das funções incidem sobre os processos fisiológicosepsicológicos do trabalhador (Kogi, 2001). Martin e Gadbois (2007) explicam em seu estudo sobre ergonomia em hospitais que as atividades dos profissionais da saúde nesse ambiente apresentam elevado nível de complexidade das informações, o que repercute em uma atividade intensamente cognitiva. 0 técnico deenfermagem relacionou ambasasvariáveis organizacionais com o adoecimento físico manifestado pela arritmia cardíaca e problemas de ordem social, 0 que vai ao encontro dos resultados da pesquisa de Costa et al. (2000), e de Barthe et al. (2007).
As evidências científicas sobre a relacão entre estresse ocupacional e enfermidades cardiovasculares intensificaram-se a partir da década de 1980 (Theorell \& Johnson, 2001). Os resultados dosestudosepidemiológicosfundamentadosno modelo demanda-controle de Karasek (2001) demonstram que os trabalhadores expostos a longo período de tempo a altas demandas de exigência psicológica ecom baixo controle sobre as variáveis ocupacionais que incidem diretamente sobre eles, apresentam maior risco de desenvolver um padrão orgânico de ativação neuro-hormonal. Isso podeinfluenciaro surgimento de patologias no sistema cardiovascular, principalmente cardiopatias coronarianas ateroscleróticas e infarto do miocárdio. Esta última morbidade é manifestada constantemente por trabalhadores com atuação em turnosalternados. Heinemann, Enderlein eStark(2001) afirmam que o efeito do estresse ocupacional proveniente de fatores psicossociais, como é o caso da variável organizacional excesso de carga horária, pode ocasionarangina, ataquecardíaco, insuficiênciacardíaca e alteração no ritmo cardíaco.

O modelo de demanda-controlede Karasek (2001), (Figura 2), pode ser aplicado neste estudo de caso a fim de obter uma melhor compreensão dos possíveis causadores do adoecimento cardíaco do participante. No caso, a variável excesso de carga horária e turnos alternados, responsáveis pelas 28 horas de estado de vigília ininterrupto, são postas na dimensão exigências psicológicas alcançando um alto nível. Por outro lado, o participante relatou que durante 0 período em que permaneceu sob esse constrangimento era privado de horas de descanso. Assim, a dimensão de decisão ou controle obtém um nível baixo. A resultante do cruzamento das duas dimensões é o quadrante 1 da diagonal A, ou seja, muita tensão incidindo sobre a saúde física e psicológica do trabalhador. Portanto, é possível conjeturar que a arritmia cardíaca manifestada pelo participante seja fruto dos 10 anos em que permaneceu sob o constrangimento de carga horária e turnos alternados de trabalho.

\section{Riscos de acidentes de trabalho e ooping}

O ambiente hospitalar apresenta vários riscos a acidentes de trabalho e riscos à saúde dos profissionais que atuam nesse tipo de instituição, como mostra Martin e Gadbois (2007), Boclin (2007), ABE/RJ (2006), Campos (2006), Balsamo 
e Felli (2006), Hökerbereg et al. (2006), NR 32 (2005), O sório et al. (2005), Nishide et al. (2004) e Oliveira e Murofuse (2001). A privação do sono eleva o risco de acidentes, como mostra Dinges, Pack, Williams, Gillen e Powell (1997) em uma pesquisa internacional onde investigaram os efeitos acumulados da escassez de sono, na qual os participantes dormiam em média 4,5 horas. Os resultados apontaram que a sonolência alcançou níveis da privação total de sono, e houve aumento das chances de ocorrência de acidentes de trabalho. Outra pesquisa internacional sobre privação de sono e acidentes de trabalho (G old et al., 1992) com 678 enfermeiras como participantes, demonstrou em seusresultadosum aumento no risco deacidentes motivados por cochilos e sonolências no desempenho das funções, bem como no trânsito durante 0 deslocamento tanto para ir como para retornar do trabalho.

Ao recortar das pesquisas sobre acidentes de trabalho as variáveis tempo, que o profissional exerce na ocupação, efrequência de acidentes, chegase a uma curva (Costa e Costa, 2003). Na área da Saúde e Segurança do Trabalho e na Biossegurança é conhecida como curva de acidentes, a qual expressa que o maior número de acidentes acontece ou no início da carreira do trabalhador, geralmente motivados pela carência de experiência ou receio, ou quando apresenta experiência considerável, quase sempre por excesso de confiança e negligência.

A partir de 1993, o participante passou a ter como atividade de trabalho a ocupação de técnico de enfermagem do ambulatório médico de uma instituição prisional de Santa Catarina. Os resultados demonstram que nessa função ele pode atuar em situações constrangedoras devido a fugas, rebeliões e com a presença de detentos e agentes prisionais com estados de humor alterados. Esse contexto proporciona que seus atores vivenciem um estado de estresse psicológico, que no caso do participante pode converter-se em riscos de incidentes e acidentes de trabalho.

Todas as evidências bibliográficas apontadas nesta seção e as situações de trabalho vivenciadas pelo técnico de enfermagem em seus 34 anos de experiência indicam elevada probabilidade de no mínimo ter sofrido um acidente de trabalho, porém, esse fato é inexistente em seu histórico ocupacional. A relação funcional de carga de trabalho (Frutuoso \& Cruz, 2005) pode ser aplicada nesse caso para auxiliar sua compreensão.
A ambiência hospitalar e a situação de estresse da instituição prisional ocupam o lado que pende paraas exigências da tarefa (Figura 1, parteinferior). A sonolência decorrente da privação de sono no período em que trabalhava sob um regime de 28 horas em estado de vigília, pode ser considerada como risco potencial ou adicional (Figura 1, parte superior). A soma de todas essas variáveis torna considerável a carga das exigências da tarefa.

A literatura sobre coping (Lazarus \& Folkman, 1984a; Lazarus\& Folkman, 1984b; Lazarus, 1966) oportunizou aos pesquisadores conjeturarem que a atitude do participante na atividade de trabalhador da saúde desde o princípio para manter o controledesuas emoções, sem pânico emovimentos rápidos diante das situações de estresse, pode ser compreendida como o coping que ele sempre utilizou em postos de trabalho nos quais atuou. Por isso, há possibilidades de considerar esse oping como sua capacidade psicofisiológica de resposta (Figura 1, parte inferior) as exigências significativas de sua tarefa. A eficácia desse coping provavelmente contribuiu para equilibrar a balança que representa a carga de trabalho, que consequentemente manteve a ausência de acidentes de trabalho.

\section{CONSIDERAÇÕES FINAIS}

0 participante da pesquisa mostrou-se como um representante do adoecimento que o os profissionais dacategoriaprofissional daenfermagem estão sujeitos. As variáveis organizacionais do ambiente hospitalar podem configurar-se como fatores de risco ao estresse ocupacional, e ocasionar um desequilíbrio na carga de trabalho, gerando uma sobrecarga para o trabalhador.

O adoecimento cardíaco, manifestado pela arritmia cardíaca, provavelmente teve uma contribuição da exposição aos fatores de risco estressores carga horáriaeturnos alterados detrabalho por aproximadamente 10 anos de uma vidalaboral de 28 horas ininterruptas em estado de vigília.

Quanto à ausência de acidentes de trabalho no histórico ocupacional do participante, a intenção dospesquisadoresnão foifazề-lo um herói, tampouco que os demais trabalhadores da saúde devam apresentar o mesmo oping que ele. Objetivou-se levar ao conhecimento dos leitores dois fatos: 0 quanto o ambientehospitalaréhostilaseu trabalhador; os fenômenos psicológicos podem contribuir para a 
prevenção de acidentes de trabalho no ambiente hospitalar, é o caso do coping em que o participante da pesquisa mostra o quanto ele pode ser eficaz.

\section{AGRADECIMENTOS}

Ao profo Dr. Roberto Moraes Cruz, à prof ${ }^{\mathrm{a}} \mathrm{D} \mathrm{r}^{\mathrm{a}}$ Joselma Tavares Frutuoso, à MSc Beatriz Marcondes de Azevedo, aos colegas Alexsandro Luiz de Andrade e ao João Fernando Rech Wachelke. Ao participante da pesquisa pela disponibilidade em colaborar com estainvestigação ao descrever suas idiossincrasias como trabalhador da saúde, os pesquisadores consideram toda a atividade de trabalho como algo muito pessoal, alcançando o fórum íntimo do trabalhador.

\section{REFERÊNCIAS}

Associação Brasileira de Enfermagem - Seção RJ. (2006). Cartilha do trabalhador de enfermagem: Saúde, segurança e boas condições de trabalho. Rio de Janeiro. ABEn.

Azevedo, A. B., \& Cruz, R. M. (2006). O processo de diagnóstico e de intervenção do psicólogo do trabalho. Cadernos de Psicologia Social e do Trabalho, 9(2), 89-98.

Balsamo, A. C., \& Felli, V. E. A. (2006). Estudo sobre os acidentes de trabalho com exposição aos líquidos corporais humanos em trabalhadores da saúde de um hospital universitário. Revista latino-americana de enfermagem, 14(3), 346-353.

Barthe, B., Gadbois, C., Prunier-Poulmaire, S., \& Q uéinnec, Y. (2007). Trabalhar em horários atípicos. In P. Falzon. (O rg.). Engonomia. (pp. 97-110). São Paulo: Blucher.

Boclin, K. L. S. (2007). Acidentes de trabalho em servidores públicos do setor saúde do estado de Santa Catarina, Sindicato dos Trabalhadores em Estabelecimentos de Saúde de Florianópolis (SINDSAÚDE), Centro Estadual de Referência em Saúde do Trabalhador de Santa Catarina (CEREST / SC), Gerência de Saúde do Trabalhador. Florianópolis: SIND SAÚDE.
Campos, I. C. M. (2006). Diagnóstico de transtornos mentais e comportamentais e relação com o trabalho de servidores públicos estaduais. Dissertação de Mestrado, D epartamento de Pós-Graduação de Psicologia da Universidade Federal de Santa Catarina, Florianópolis.

Conselho Nacional de Saúde (1996). Resolução nํㅜ 196 de 10 de outubro de 1996. Diário Oficial da União, Poder Executivo, de 16 de outubro.

Costa, M. A. F., \& Costa, M. F. B. (2003). Biossegurança de A a Z. Rio de Janeiro: Papel Virtual.

Costa, E. S., Morita, I., \& Martinez, M. A. R. (2000). Percepção dos efeitos do trabalho em turnos sobre a saúde e a vida social em funcionários da enfermagem em um hospital universitário do Estado de São Paulo. Cadernos de Saúde Pública, 16(2), 553-555.

Dinges, D. F., Pack, F., Williams, K., Gillen, K. H., Powell, J. W., \& Ott, G. E. (1997). Cumulative sleepiness, mood disturbance and psychomotor vigilance performance decrements during a week of sleep restricted to 4-5 hour per night. Sleep, 20(4), 266-277.

Falzon, P., \& Sauvagnac, C. (2007). Carga de trabalho e estresse. In P. Falzon, (O rg.). Ergonomia. (pp. 141-154). São Paulo: Blucher.

Fischer, F. M., Teixeira, L. R., Borges, F. N. S., Gonçalves, M. B. L., \& Ferreira, R. M. (2002). Percepção de sono: duração, qualidade e alerta em profissionais da área da enfermagem. Cadernos de Saúde Pública, 18(5), 1261-1269.

Flick, U. (2004). Uma introdução à pesquisa qualitativa (2a ed.). Porto Alegre: Bookman.

Frutouso, J. T., \& Cruz, R. M. (2005). Mensuração da carga de trabalho e sua relação com a saúde do trabalhador. Revista Brasileira de Medicina do Trabalho, 3(1), 29-36.

Gold, D. R., Rogacz, S., Bock, N., Tosteson, D., Baum, T. M., \& Speizer, F. E. (1992). Rotating shift work, sleep, and accidents related to sleepiness in hospital nurses. American jounal of public health, 82(7), 1011-1014.

Heinemann, L., Enderlein, G., \& Stark, H. (2001). El concepto de factor de riesgo en la enfermedade cardiovascular. In Enciclopedia de Salud y Seguridad em el Trabajo (pp. 5-9). España: Ministerio de Trabajo y Assuntos Sociales. 
Hökerberg, Y. H. M., Santos, M. A. B., Passos, S. R. L., Rozemberg, B., Cotias, P. M. R., \& Alves, L. (2006). O processo de construção de mapas de risco em um hospital público. Ciência \& Saúde Coletiva, 11(2), 503-513.

Jex, S. M. (1998). Stress and job performance. Londres: Sage.

Karasek, R. A. (1979). Job demands, job decision latitude, and mental strain: Implications for job redesign. Administrative science quarterly, 24, 285-208.

Karasek, R. A. (2001). El modelo de demandascontrol: Enfoque social, emocional e fisiológico del riesgo de estres e dejarollo de comportamientos activos. In Enciclopedia de Salud y Seguridad em el Trabajo (pp. 6-16). España: Ministerio de Trabajo y Âssuntos Sociales.

Kogi, K. (2001). Privacion del sueño. In Enciclopedia de Salud y Seguridad em el Trabajo (pp. 56-60). España: Ministerio de Trabajo y Assuntos Sociales.

Lazarus, R. S. (1966). Psychological stress and and the coping process. New York: McG raw.

Lazarus, R. S., \& Folkman, S. (1984a). Coping and Adaptation. In W. D. Gentry (O rg.). Handbook of Behavioral Medicine. (pp. 282-325). New York: The Guilford Press.

Lazarus, R. S., \& Folkman, S. (1984b). Stress, appraisal, coping. New York: Springer.

Lakatos, E. M., \& Marconi, M. A. (1996). Técnicas de pesquisa ( 3 a ed.) São Paulo: Atlas.

Martin, C., \& Gadbois, C. (2007). A ergonomia no hospital. In P. Falzon (O rg.). Ergonomia. (pp. 519-534). São Paulo: Blucher.

Marziale, M. H. P., \& Robazzi, M. L. C. C. (2000). O trabalho de enfermagem e a ergonomia. Revista Latino-Americana de Enfermagem, 8(6), 24-127.

Ministério do Trabalho. (1994a). Norma Regulamentadora No 9: Programa de prevenção de riscos ambientais (PPRA). Brasília: Ministério do Trabalho.

Ministério do Trabalho. (1994b). Portaria no 25, de 29 de dezembro de 1994. Modifica a Norma Regulamentadora No 5 e estabelece procedimentos para elaboração do mapa de riscos. Brasília: Ministério do Trabalho.
Ministério do Trabalho. (2005). Norma Regulamentadora No 32: Segurança e saúde no trabalho em servicos de saúde. PORTARIA, $N .^{\circ} 485$, de 11 de novembro, Seção 1 Brasília: Ministério do Trabalho.

Murta, S. G., \& Tróccoli, B. T. (2007). Stress ocupacional em bombeiros: Efeitos de intervenção baseada em avaliação de necessidades. Estudos de Psicologia, 24(1), 41-51.

Nished, V. M., Benatti, M. C. C., \& Alexandre, N. M. C. (2004). O corrência de acidente de trabalho em uma unidade de terapia intensiva. Revista Latino-Americana de Enfermagem, 12(2), 204-211.

Oliveira, B. R. G., \& Murofuse, N. T. (2001). Acidentes de trabalho e doença ocupacional: estudo sobre o conhecimento do trabalhador hospitalar dos riscos à saúde de seu trabalho. Revista Latino-Americana de Enfermagem, 9(1), 109-115.

O sório, C., Machado, J. M., \& Minayo-Gomez, C. (2005). Proposição de um método de análise coletiva dos acidentes de trabalho no hospital. Cadernos de saúde pública, 21(2), 517-524.

Pinheiro, F. A., Tróccoli, B. T., \& Tamayo, M. R. (2003). Mensuração de coping no ambiente ocupacional. Psicologia: Teoria e pesquisa, 19(2), 153-158.

Tamayo, M. R., \& Tróccoli, B. T. (2002). Exaustão emocional: relações com a percepção de suporte organizacional e com as estratégias de coping no trabalho. Estudos de Psicologia, 7(1), 37-46.

Theorell, T., \& Johnson, J. V. (2001). Enfermedades cardiovasculares. In Enciclopedia de Salud y Seguridad em el Trabajo (pp. 67-68). España: Ministerio de Trabajo y Assuntos Sociales.

Yin, R. K. (2005). Estudo de caso: Planejamento e métodos. (3a ed.). Porto Alegre: Bookman.

Recebido: 26/ 09/ 2007 Received: 09/ 26/ 2007

A provado: 19/ 08/ 2008 A pproved: 08/ 19/ 2008 